\title{
Application of natural magnesium-containing solution in correction heart failure in experiment
}

\begin{abstract}
In the pathogenesis of heart failure, one of the leading places is occupied by disturbances in the redox processes in the main energy cycles in cardiomyocytes. According to modern concepts, the magnesium ion is one of the major macronutrients that activate the enzymes of these reactions. The use of mineral water with a high content of magnesium in white rats with heart failure had a significant corrective effect on cardiovascular parameters.
\end{abstract}

Keywords: heart failure, white rats, redox processes, magnesium

\author{
Volume 8 Issue 3 - 2019
}

\begin{abstract}
Gushcha Sergey G, Nasibullin Boris A, Polshakova Tatyana V,Volyanska Veronika S, Balashova Irina V, Bondar Yulia P

Ukrainian Research Institute of Medical Rehabilitation Therapy of Ministry of Health of Ukraine, Ukraine
\end{abstract}

Correspondence: Gushcha Sergey G, State Institution, Ukrainian Research Institute of Medical Rehabilitation Therapy of Ministry of Health of Ukraine, Lermontovskyi bystreet, 6 , Odessa, Ukraine, 650I4, Email gushchasergey@rambler.ru

Received: April 27, 2019 | Published: May 06, 2019

\section{Introduction}

Cardiovascular diseases are the leading cause of disease burden and deaths globally. ${ }^{1-3}$ The UN, alarmed by the increasing burden of noncommunicable diseases (NCDs) and high disease severity and casefatality in low-income and middle-income countries compared with high-income countries, acknowledged in 2012 that the rising burden of NCDs was one of the major threats to sustainable development in the 21 st century. ${ }^{4,5}$

This determines the relevance of the search for new effective and affordable methods of treatment of cardiovascular diseases (CVD). In this case, therapeutic approaches are based on dietary recommendations, physical activity regimen, prolonged use of several classes of medications, which may be accompanied by side effects and insufficient efficacy of therapy. Recently, considerable attention has been given to non-drug methods of treatment, and in particular to mineral waters (MB). ${ }^{6}$ Mineral water due to the presence in their composition of many macro-and micronutrients and biologically active substances, have a powerful biological and therapeutic effect. ${ }^{7-9}$ However, they do not have side effects and allergic reactions, contribute to the removal of metabolic products. ${ }^{9}$ In the context of this, the use of natural mineral waters of various balneological types in the complex treatment of CVD is promising. ${ }^{11}$

Magnesium plays an important role in the implementation of physiological, metabolic, immunological processes in humans and animals, despite all this active center of enzymes of oxidation and phosphorylation: ATP and enzymes that take part in the metabolism of creatine phosphate; with the participation of $\mathrm{K}^{+}-\mathrm{Mg}^{2+}$ dependent ATP, the energy supply of transmembrane transport of ions, primarily in myocytes, is carried out. ${ }^{12,13}$ Magnesium is involved in the regulation of glycolysis, $\mathrm{Na} / \mathrm{K}$ membrane pump activity, participates in processes of neuromuscular excitability, etc. ${ }^{14-16}$

Because of magnesium's many functions within the body, it plays a major role in disease prevention and overall health. Low levels of magnesium have been associated with a number of chronic diseases including migraine headaches, Alzheimer's disease, cerebrovascular accident (stroke), hypertension, cardiovascular disease, and type 2 diabetes mellitus. ${ }^{17}$ In connection with the above, it is of scientific and practical interest to study the action of mineral waters containing magnesium in high concentrations on the development of a model of heart failure in white rats.

\section{Methods}

To investigate the role of magnesium deficiency in the pathogenesis of cardiovascular diseases, a model of heart failure (HF) was recreated in rats, and the effect of natural liquid balneotherapeutic agent "Magnesium oil" was investigated with a total mineralization of $350 \mathrm{~g} / \mathrm{dm}^{3}$ and magnesium concentration $\left(\mathrm{Mg}^{+2}\right)-100 \mathrm{~g} / \mathrm{dm}^{3}$, diluted to $40.0 \mathrm{~g} / \mathrm{dm}^{3}$. Reproduction of the HF model in white rats of female weighing 180-210g and at the age of 9 months was carried out by single injection subcutaneously in the right hip of an oil suspension of phosphorus at the rate of $10 \mathrm{mg} / \mathrm{kg}$ body weight, while in the left thigh intramuscularly injected $\mathrm{ml}$ of $1 \%$ solution of vitreous.

\section{Analysis}

\section{Characterization of the HF model and features of the use of "Magnesium oil"}

The HF model was verified on a 14-day basis to determine the frequency of respiration, heart rate, adenosine triphosphotase (ATP) activity and structural changes in the heart tissue. "Magnesium oil" was introduced the next day after the reproduction of the pathology, intragastric in a dose of $1 \%$ of the mass every day, course for 12 days. Intact animals served as a comparison group.

\section{Pathogenesis of the HF model}

In rats with a $\mathrm{CH}$ model at day 14 , an increase in the respiratory rate by $10 \%$ was found on $(\mathrm{p}<0.01)$, and the heart rate per minute by $5 \%(\mathrm{p}<0.01)$. Microscopically, a fascicle and layer organization is maintained in the myocardium. Interpunched layers are swollen thick, vessels are sharply full-blooded. Cardiomyocytes are pale, without lumbar puncture, indurated, densely colored. Consequently, certain signs of dystrophic changes in the myocardium are identified. Histochemical studies showed a reduction in the activity of succinate dehydrogenase (SDH) and lactate dehydrogenase (LDH) in the tela of the myocardium by $50 \%(\mathrm{p}<0.001)$ : the activity of the SDH was $(3.50 \pm 0.41)$ of the standard density units (unit dose densities) - 
against $(7,00 \pm 0,15)$ mind. unit op dense in norm. LDH activity was $(3,00 \pm 0,27)$ of mind. unit op dense -against $(6,00 \pm 0,19)$ of mind. unit wholesale. in norm. That is, inhibition of the activity of oxidativereducing enzymes is observed. Also, the decrease of activity in the tissue of the myocardium $\mathrm{Mg}^{2+}$-dependent $\mathrm{K}^{+} / \mathrm{Na}^{+}$-ATPase was determined $77 \%(\mathrm{p}<0.001)$ and $\mathrm{Mg}^{2+}$-dependent $\mathrm{Ca}^{2+}$-ATPasein $46 \%(\mathrm{p}<0.01)$ indicates the suppression of energy-dependent processes of transmembrane transport.

\section{Corrective effect of "Magnesium oil" on the course (development) of the HF model}

Under the influence of the course conducted with "Magnesium Olive", a reduction in the respiration rate and heart rate to control group $(\mathrm{p}>0.1)$ was determined. The activity of $\mathrm{Mg}^{2+}$-dependent $\mathrm{K}^{+} /$ $\mathrm{Na}^{+}$-ATPase and $\mathrm{Mg}^{2+}$-dependent $\mathrm{Ca}^{2+}$-ATPase in cardiomyocytes increased by $50 \%(\mathrm{p}<0.01)$ and by $30 \%(\mathrm{p}<0.01)$, exceeded the control values. In the myocardium the tufts organization has been saved. Between bunch layers are thick enough, thin. Fibroblasts with dark oval cores. Vessels of moderate stagnant blood flow. Cardiomyocytes are pale colored, but in most of them, there is a fairly distinct lumbar euphemism. The nuclei of cardiomyocytes are oval, dark colored. The activity of the oxidative-reducing enzymes has increased: the value of SDG and LDH was in cardiomyocytes $(5,00 \pm 0,21)$ and $(5,00 \pm 0,15)$ of mind. unit op dense. It should be emphasized that significant restoration of the structure of the myocardium ensured the restoration of the activity of the studied parameters of the cardiovascular system - respiratory rate and heart rate.

\section{Conclusion}

Thus, application of the rather serious model of heart failure of the balneotherapeutic agent "Magnesium Olive" has a noticeable corrective effect: it leads to almost complete disappearance of the structural signs of dystrophic changes in the myocardium, while partially restores the activity of oxidative-reducing enzymes of EDD and LDH and enzymes in energy production $-\mathrm{Mg}^{2+}$-dependent $\mathrm{K}^{+} /$ $\mathrm{Na}^{+}-$ATPase and $\mathrm{Mg}^{2+}$-dependent $\mathrm{Ca}^{2+}-$ ATPase, and completely restores the breathing rate and heart rate.

\section{Acknowledgments}

None.

\section{Conflicts of interests}

The authors declare that there is no conflict of interests.

\section{References}

1. Dorairaj Prabhakaran, Panniyammakal Jeemon, Meenakshi Sharma, et al. The changing patterns of cardiovascular diseases and their risk factors in the states of India: the Global Burden of Disease Study 1990-2016. Lancet Glob Health. 2018;6:e1339-1351.
2. Hinton W, McGovern A, Coyle R, et al. Incidence and prevalence of cardiovascular disease in English primary care: a cross-sectional and follow-up study of the Royal College of General Practitioners (RCGP) Research and Surveillance Centre (RSC). BMJ Open. 2018;8(8):e020282.

3. Biglu MH, Ghavami M, Biglu S. Cardiovascular diseases in the mirror of science. J Cardiovasc Thorac Res. 2016;8(4):158-163.

4. Ralston J, Reddy KS, Fuster V, et al. Cardiovascular diseases on the global agenda: the United Nations high level meeting, Sustainable Development Goals, and the way forward. Glob Heart. 2016;11:375-379.

5. UN General Assembly. Resolution adopted by the General Assembly on 27 July 2012:the future we want (A/RES/66/288).

6. Maraver F, Karagülle MZ. Medical Hydrology and Balneology: Environmental Aspects. Balneo Serie de monografias. 2012;6:465.

7. Zabolotna IB, Gushcha SG, Mikhailenko VL. Non-alcoholic fatty liver disease and mineral waters of Ukraine - opportunities of application (experimental-clinical studies). Balneo Research Journal. 2018;9(3):270 276.

8. Albertini MC, Dacha, Teodori, et al. Drinking mineral waters: biochemical effects and health implications - the state of the art. Int J Environmental Health. 2007;1(154):153-169.

9. Quattrini S, Pampaloni B, Brandi ML. Natural mineral waters: chemical characteristics and health effects. Clin Cases Miner Bone Metab. 2016;13(3):173-180.

10. Nasibullin BA, Plakida AL, Trubka IA, et al. Comprehensive assessment of functional changes in the organism of healthy rats in external and internal use of silicone low mineralized mineral water. European Journal of Clinical and Biomedical Sciences. 2018;4(1):1-5.

11. Kolodenko EV, Zukov W. The efficiency of rehabilitation of patients with coronary heart disease after surgical myocardial revascularization with violation of carbohydrate metabolism. Journal of Education, Health and Sport. 2015;5(11):142-150.

12. Di Nicolantonio JJ, Liu J, O Keefe JH. Magnesium for the prevention and treatment of cardiovascular disease. Open Heart. 2018;5:e00775.

13. Schwalfenberg GK, Genuis SJ. The Importance of Magnesium in Clinical Healthcare. Scientifica (Cairo). 2017;4179326.

14. Al Alawi AM, Majoni SW, Falhammar H. Magnesium and Human Health: Perspectives and Research Directions. Int J Endocrinol. 2018: 9041694

15. Guerrero-Romero F, Rodriguez-Moran M. Magnesium improves the beta-cell function to compensate variation of insulin sensitivity: doubleblind, randomized clinical trial. Eur J Clin Invest. 2011;41(4):405-410.

16. Uwitonze AM, Razzaque MS. Role of magnesium in vitamin D activation and function. J Am Osteopath Assoc. 2018;118:181-189.

17. Volpe SL. Magnesium in Disease Prevention and Overall Health. Adv Nutr. 2013;4(3):378-383. 